\title{
Language Shift and Maintenance of Ga in Accra
}

\author{
Eric Ziem Bibiebome ${ }^{*} \quad$ Jacob Anderson Ivy Jones-Mensah \\ Department of Public Relations Management, University of Professional Studies, Accra-Ghana P.O. BOX
}

LG149, LEGON-GHANA

\begin{abstract}
The situation whereby a speech community uses its language in fewer domains relating to other languages or even loses proficiency entirely in its language in favor of other languages as a consequence of urbanization is a widespread social phenomenon that affects several millions of speech communities all over the world. Some studies have been made, especially, from Western perspectives, in order to get a good understanding of this social phenomenon so that predictions can be made as regards the future status of languages, especially, subordinate languages in communities with dominants languages. The paper investigates into whether or not the Accra speech community, a highly multilingual city, is shifting from the use of Ga to other languages or is maintaining the use of Ga. The major findings of the study are that language shift situations exist more in non-typical Ga areas while language maintenance is observed in mainstream Ga communities. Some factors responsible for these linguistic phenomena results are highlighted. The results of this study led to the recognition of the need for the Gas to cultivate positive attitude towards their language in domains beyond their homes and the need for adequate language planning in order to assure of maintenance of the native language.
\end{abstract}

Keywords: language shift, language maintenance, speech communities, multilingual.

DOI: $10.7176 / \mathrm{JEP} / 10-15-11$

Publication date:May $31^{\text {st }} 2019$

\subsection{Introduction}

Language is one of the most powerful tools of social organization and control and has over the years demonstrated to be central and crucial in the society. Everyday as societies interact with one another, the issue of language contact comes into play. In the words of Mesthrie, Swann, Duemert, and Leap (2000:248), "language contact sometimes occurs when there is increased social interaction between people from neighboring territories who have traditionally spoken different languages." In reference to some sociolinguistic works such as Janse (2003), Batibo (2005), Wardhaugh (1987), and Myers-Scotton (2006), when languages come into contact with one another, any of the following outcomes is possible. The speech communities may decide to maintain their respective languages in all domains, they may also choose to use both their native language and the newly introduced language in specifiable domains, or they may rely on the new language rather than their indigenous language in all or most domains. In all of the outcomes mentioned above, one linguistic phenomenon that is likely to arise as a result is multilingualism which is speaker's ability to use two or more languages.

Talking about language contact, we can mention the linguistic situation of Accra, the largest and busiest city in Ghana. Accra has various ethnic groups each of which speaks a different language. As a proof of this, the population and housing census conducted in Ghana in the year 2000, for instance, showed that Accra is made up of 1,065,509 Akans, 794,881 Ga- Dangbes, 481, 583 Ewes and 77,459 Guans. Obviously, from a result of this nature, one can easily say that almost close to every one of Ghana's forty-nine or so languages have representatives in the country's capita-Accra. The result of this influx has been the gradual transformation of Accra from being largely monolingual to a vibrant collection of multilingual societies. In other words, multilingualism which is typical of the African linguistic situation is a common thing to come across in Accra.

As history will let us understand, the issue of Accra as a hub of different languages or a center of multilingualism has not been a recent happening. In 1966, Reindorf reports that Accra has always been occupied by other ethnic groups particularly the Akans. Agbedor (1994:35) also in a similar fashion says that "in Accra, the dominance of Ga may be for purely geographical reasons" and that "the influx of people of other ethnolinguistic groups is creating an ambivalent situation in which Akan is seriously emerging as a co-lingua Franca in the capital. This paper therefore attempts to look at the extent to which Ga speakers in Accra are either shifting from the use of Ga or maintaining the Ga language which happens to be the indigenous language of Accra.

\subsection{Language Shift and Maintenance}

Language shift represents a situation whereby for some reasons speakers may choose to "use their language in fewer domains with respect to other languages or even lose proficiency in their language altogether in favor of other language" (Bodomo, Anderson, and Dzahene-Quarshie 2009). This linguistic occurrence is not new, neither is it limited to some special place(s). Studies on this phenomenon is usually done alongside language Shift which Fishman (1966) describes as situation when a community gives up entirely its language in favor of another. In the past, available empirical literature on Language Shift and Maintenance indicated that the linguistic phenomena has 
been looked at mostly from western point of view (e.g. Fishman 1964, 1991, Veltman 1983, Bastardas-Boada 2007, Habtoor 2012, Finocchiaro 2004, and Jagodic 2011). Nevertheless, relatively current works like Aswegen (2008), Kedrebeogo (1998), and Jamai (2008) have also attempted to look at Language shift and Maintenance purely from the African perspective. More specifically, (Bodomo et al 2009) and Agyekum (2010) discussed language shift from the perspectives of Ghana, a highly multilingual developing nation in West Africa.

In the many of the researches carried out on language shift, factors like migration, industrialization, ethnicity urbanization, prestige, changes in the way of life of a group, changes in the power relationship between the groups, and stigmatized attitudes toward the minority group values and language have all been identified as promoters of language shift (see also Fishman (1964); Clampitt-Dunlap (1995). Thomason (2001:58) also explained that apart from migration, the issues of politics, economic, and social changes can also result in language shift. Interestingly, most of above mentioned factors do not just promote language shift but also interfere and slow down or prevent the shift in its totality. Kloss (2004) in providing a deeper understanding of the concept provides a checklist of factors that are likely to lead to language maintenance. These factors are the existence of language islands, high educational level of immigrants; low educational level of the minority, great numerical strength of the speakers; smallness of the group, great cultural and/or linguistic dissimilarity between minority and majority, suppression of minority tongue(s), permissive attitude of majority group, and the sociocultural characteristics of the minority group in question. These factors may however work against language maintenance.

In Ghana, Bodobo et al (2009) in their work interestingly introduced the concept of ecology of language shift, and argued that any theory of language shift must rigorously take into consideration the complexity of the ecology in which language shift occurs. They finally identified multilingual language shift processes in Ghana. In their case, the shift processes involved situations in which different types of language shift take place concurrently or sequentially in Ghana. They realized a shift from minority Languages to major regional languages and subsequently to English. Almost similar to their findings, Agyekum (2010) looked at shift in Ghana from two perspectives: language shift from a Ghanaian language to English which is the official language and shift from one or two Ghanaian languages to a third Ghanaian language that has become a lingua franca of an area.

\subsection{Methodology}

\subsection{Data collection instrument and method}

The mode of data collection for this paper was twofold. First and foremost, well-structured questionnaires with both close and open ended questions which captured the varying views and language situations that are peculiar to the Accra language landscape was distributed to respondents within the study area. This was intended to collate information like the respondents' biographical details, language proficiency and choices, individual sociolinguistic situations as well as the attitudes of respondents towards the Ga language and language maintenance strategies. The second type of data was from interviews conducted to examine how some individuals use their language within their social networks. The main objective of the second data was to verify how reflective the findings of the questionnaires are on the lives of individuals and their social networks.

In terms of selection of respondents, for the questionnaire, the respondents were randomly selected. However, this was tactically done in order to ensure that all subjects have equal chances of being selected. In this regard, respondents cut across variables like gender, age, ethnic groupings, and levels of education. This is supposed to give the selection a high and balance. As regards the interviewees, they were also tactically chosen to ensure the representations of Gas and non-Gas, as well as residents from the four selected geographical areas.

\subsection{Geographical Areas}

The geographical area was limited to four locations in Accra. The first two areas are Labadi, and Osu: these are indigenous $\mathrm{Ga}$ areas and the situation over there epitomizes the general ethnolinguistic situation in typical Ga areas. The choice of these two areas was informed by the fact that Ga is the first language of most of the inhabitants in these areas. The other two areas to be studied are Labone and Legon-Achimota area. These are non-Ga communities with population of mixed ethnolinguistic groups. The inclusion of Labone and Legon-Achimota settlements in this research was to help us know how Ga is faring in the non-Ga areas as well as the attitudes of people of other ethnic groups towards the Ga language. It was also to identify the reason(s) why some people decide to either learn or not to learn $\mathrm{Ga}$. The spread of the choice across these four areas was to ensure equal representation with respect to Gas and non- Gas residing in Accra.

\subsection{Sample size of the Population}

All in all, for the questionnaire data, fifty questionnaires was given out in each of the four areas making a total of two hundred (200) with an equal representation of both Gas and non-Gas. For the interview, two respondents were selected from each of the four areas making a total of eight respondents. The reason for this number of respondents has to do with the length of time required to do comprehensive studies on individual languages and how they are used daily in their social networks. 


\subsection{Analysis and Discussion}

The results of the survey showed that in the mainstream Ga communities, Ga commands a respectable number of speakers and still remains an integral part of the daily life of people in Accra. As it turned out, a great number of the Gas use Ga at home which is an indication of the fact that a greater number of children grow up with the Ga language as their mother tongue, and are practically proficient in it. For instance in table 1 below, it can be observed that the pattern of language use in the immediate environment demonstrated by the respondents from the typical $\mathrm{Ga}$ areas is that of monolingualism. Out of a total of 100 respondents, all of them use $\mathrm{Ga}$ at home with their parents/children and their relatives. This, however, is to be expected because all the respondents are natives of Ga and have $\mathrm{Ga}$ as their first language. Besides that, the dominant language of their immediate environment is $\mathrm{Ga}$.

\section{Table 1: Domains of use among Osu and La respondents}

\begin{tabular}{|c|c|c|c|c|c|c|c|}
\hline & $\mathrm{Ga}$ & Twi & Fante & Ewe & English & Hausa & Others \\
\hline $\begin{array}{l}\text { Home(with } \\
\text { parents) }\end{array}$ & 100 & - & - & - & 16 & - & - \\
\hline $\begin{array}{l}\text { Home(with siblings } \\
\text { and relatives) }\end{array}$ & 100 & 21 & - & - & 25 & - & - \\
\hline $\begin{array}{l}\text { Community (with } \\
\text { friends) }\end{array}$ & 100 & 45 & 4 & - & 29 & 3 & - \\
\hline $\begin{array}{l}\text { School( with } \\
\text { mates) }\end{array}$ & 41 & 28 & 1 & - & 41 & 2 & - \\
\hline $\begin{array}{l}\text { Mosque/Church(wi } \\
\text { th congregation) }\end{array}$ & 100 & 44 & 4 & - & 47 & - & - \\
\hline Workplace & 100 & 46 & - & - & - & - & - \\
\hline $\begin{array}{l}\text { Market (selling or } \\
\text { buying) }\end{array}$ & 59 & 36 & - & - & 48 & - & - \\
\hline With strangers & 61 & 35 & - & - & 4 & - & - \\
\hline
\end{tabular}

This implies that Ga has not lost its position as the language of use among the Gas in the mainstream Ga homes. Practically, the extent to which the Ga language is maintained in the home is actually a forecaster of the extent to which the language will stay alive, or disappear in successive generations.

The study also show that in the non-typical Ga areas, the respective mother tongues of individuals are maintained in the home domains. However in the societal domains, Twi is the dominant language used while English also occupies other domains. In table 2 below, for instance in the church 85 and 38 people said they will use Twi and English respectively as against 51 who said they will use Ga. 
Table 2: Domains of use among Achimota and Labone respondents

\begin{tabular}{|c|c|c|c|c|c|c|c|}
\hline & $\mathbf{G a}$ & Twi & Fante & Ewe & English & Hausa & Others \\
\hline $\begin{array}{l}\text { Home(with } \\
\text { parents) }\end{array}$ & 14 & 33 & 4 & 21 & 29 & 11 & 7 \\
\hline $\begin{array}{l}\text { Home(with siblings } \\
\text { and relatives) }\end{array}$ & 21 & 44 & 4 & 26 & 38 & 12 & 7 \\
\hline $\begin{array}{l}\text { Community (with } \\
\text { friends) }\end{array}$ & 56 & 88 & 4 & 26 & 47 & 12 & 7 \\
\hline $\begin{array}{l}\text { School( with } \\
\text { mates) }\end{array}$ & 19 & 38 & - & 2 & 40 & - & - \\
\hline $\begin{array}{l}\text { Mosque/Church(wi } \\
\text { th congregation) }\end{array}$ & 51 & 85 & 4 & 26 & 38 & 6 & 7 \\
\hline Workplace & 15 & 56 & 2 & 18 & 64 & 4 & 5 \\
\hline $\begin{array}{l}\text { Market (selling or } \\
\text { buying) }\end{array}$ & 45 & 90 & - & - & 5 & 9 & - \\
\hline With strangers & 13 & 87 & - & - & 42 & - & - \\
\hline
\end{tabular}

Clearly, Twi seems to be emerging as the second language of many residents in Accra since it serves as the medium of inter-ethnic communication and is the preferred medium of education beyond the home domain. This can be more linked to the issue of numerical strength and dominance of Twi speakers than any perception of reputation given to the language. With respect to Ga, despite the fact that speakers in this area claim to understand the language they hardly use it. In the end, Ga is relegated to special times and specific domains.

It also interesting to note from the survey that Twi and English have managed to encroach on some domains in the mainstream Ga societies. Just beyond the home, Twi also commands a good number of speakers and is used for inter-ethnic communication in the traditional Ga societies. As it panned out, most people, both Gas and nonGas have it at the back of their mind that everyone understands Twi and so, strangers are approached in Twi. As table 1 show, in the typical Ga areas 61 people said they first use Ga with strangers and as many as 35 respondents claimed to approach strangers in Twi, and sometimes English. This, perhaps, is evidence of the spread of Twi in the country.

\subsection{Conclusion}

Based on the facts presented and the outcome of the survey conducted, one can safely say that the linguistic situation in certain parts of Accra, especially in the non-traditional Ga areas, is marked with language shift possibilities. That is, certain factors were identified in such areas in Accra which have gradually compelled some speakers to use more of other languages in domains previously tagged as Ga domains. What we see now is the shrinking trend of Ga domains in such areas.

From the survey conducted, English and Twi dominated in most domains within the boundaries of the nontypical $\mathrm{Ga}$ areas whilst $\mathrm{Ga}$ also dominated in most of the domains within the traditional $\mathrm{Ga}$ areas. However, whilst Twi and, sometimes, English are slowly entering into the societal domains of the traditional Ga areas, Ga on the other hand is doing badly in the non- typical Ga areas like Labone, Achimota and so on. The interpretation of this is that although Ga acts as a lingua franca and is still vibrant and commands a respectable number of speakers in the mainstream $\mathrm{Ga}$ areas, it is not widely used in the remaining non-Ga areas.

\subsection{Factors for loss of Ga Domains}

\subsubsection{Pressure from other languages}

$\mathrm{Ga}$ in its homeland faces strong competition for domains, particularly, from both $\mathrm{Ga}$ and Twi. These two languages have encroached more on domains formerly labeled as Ga domains. Unlike English where people are lured to learn to speak for reason of prestige, the underlying reason for learning Twi is number and the dominance of Twi speakers. Most people in Accra use Twi because they see it as the most appropriate medium for interethnic communication. 
The status of Twi in Accra, presently, does not deviate the least from what Batibo (2005) describes as language of areal importance. This means that although Twi commands a wide number of speakers and is widely spoken, its area of power is yet to get to the level of national status. Moreover, although it plays a significant role as a lingua franca, its functions are restricted to very basic domains as compared to English.

5.1.2 Attitude of Ga speakers

Ideally, since $\mathrm{Ga}$ is the native language of Accra, the general expectation is that the majority of the people residing there, both natives and non-natives would speak the language. On this particular score, more than $90 \%$ of the respondents reported to understand $\mathrm{Ga}$ in varying degrees. Although this statistics seems to be an encouraging one, little can be said of the attitudes of these same people with respect to the usage of the language. Despite the fact that most people (both natives and non-natives) understand $\mathrm{Ga}$ in varying degrees, they use more of other languages rather than $\mathrm{Ga}$; hence, the gradual loss of $\mathrm{Ga}$ domains. This development is best attributed to the fact already established that other languages have been gradually integrated into the linguistic composition of Accra, and this has subsequently affected the attitude and language choice of speakers who now have the luxury of choosing from a repertoire of languages. From the survey, it looks like Ga is valued by speakers within the traditional areas because it serves as the identity of the Gas, but the story is different in the non- Ga areas because of alternative languages like Twi, English, and other local languages which are greatly depended on. This attitude of being proficient in Ga but not ready to use it is certainly not positive and absolutely unfavorable to the language maintenance efforts and leads to wearing away of language proficiency which will result in the shift or loss of domains.

\subsubsection{Inadequate enforcement of language policies}

Beyond the reasons of numbers and pride which have lured more speakers to use Twi and English in Accra there is also the issue of inadequate enforcement of language policies that have been formulated over the years to preserve the Ghanaian languages. Various attempts have been made in varying degrees to fuse the Ghanaian local languages into the educational system and all of these seem to $r$ recommend the use of the dominant local language of the area at the early part of the basic education. If these policies are to be strictly implemented, then at least, Ga will also have its full share in the schools in Accra, but, from what was observed, the story has been different. Apart from English which has become the official medium of teaching in the schools, local languages like Twi, Fante, and Ewe serve as alternative subjects to the study of the Ga language in schools in Accra. The observation made in most schools in Accra is that, an encouraging number of students who are given the opportunity to choose between $\mathrm{Ga}$ and other languages end up doing the other local languages and not $\mathrm{Ga}$. This was more observed in schools located within the non-traditional Ga areas.

\subsection{Recommendations}

The maintenance of the Ga language cannot be mentioned without mentioning the attitude of speakers. There is the need for speakers, especially, Gas to adopt positive attitudes towards their language; they should be prepared to speak the language in all domains and with everyone. When this happens, other speakers may be compelled to use the Ga language in more domains. The study also points to the need for the Ga speech community to come together and take pragmatic steps to protect Ga from further losing more of its domains. They can do this by organizing programs to instill into their people (especially, the children) the value of their language.

The need for sufficient language planning in order to ensure the continuous existence of our local languages, especially, Ga. In doing this, the issue of how other languages have been integrated into the linguistic structure of the capital city should also be taken into consideration. If possible there should be clear cut domains for the various languages in order to reduce the level of encroachments of domains of the Ga language by dominant languages. We should also in the course of the planning not fail to provide adequate support for our institutions that will be responsible for implementing, enforcing, and spreading information connected to policy formation and implementation and educating the public on the effects of such policy on them. Hopefully, the lesson that will be gathered from the case of $\mathrm{Ga}$ in Accra will contribute to future planning efforts in other places.

\section{References}

Aswegen, V. G. (2012), "Language Maintenance and Shift in Ethiopia: The Case of Maale”, Theory and Practice in Language Studies, Vol. 2, No. 5, pp. 945-955. Academy Publisher.

Agyekum, Kofi. (2010), "Language Shift: A Case Study of Ghana”, Sociolinguistic Studies. 3.10.1558/sols.v3i3.381.

Bastardas-Boada, A. (2007), "Linguistic sustainability for a multilingual humanity", Glossa. An Interdisciplinary Journal (on-line) 2(2).

Batibo, H. (2005), "Language Decline and Death in Africa: Causes, Consequences and Challenges", Toronto: Multilingual Matters Ltd.

Bodomo, A., Anderson, J., \& Dzahene-Quarshe, J. (2009), “A Kente of many colours: Multilingualism as a complex ecology of Language Shift in Ghana”, http://www.equinoxjournals.com/ojs/index.php/SS/index 
Clampitt-Dunlap, S. (1995), "Nationalism, Native Language Maintenance and the spread of English: A Comparative study of the cases of Guam, the Philippines and Puerto Rico", PhD Thesis. University of Puerto Rico.

Dzameshie, Alex. K. (2006), "Language Policy of the Less Diffused Languages of Ghana”, University of Ghana.

Fasold, R. (1984), "The sociolinguistics of society", New York: Basil Blackwell, Inc.

Fishman, J. A. (1964), "Language maintenance and language shift as a field of inquiry", Linguistics 9: 32-70.

Fishman, J.A. (1966), "Language Loyalty in the United States", The Hague: Mouton.

Finocchiaro, C. M. (2004), "Language Maintenance/Shift of a Three-Generation Italian Family in Three Migration Countries: An International Comparative Study", PhD Thesis, Department of Linguistics and Applied Linguistics, the University of Melbourne.

Habtoor, H. A. (2012), "Language Maintenance and Language Shift among Second Generation Tigrinya-speaking Eritrean Immigrants in Saudi Arabia", PhD Thesis, Department of English, College of Education at Shabwah, Aden University.

Jamai .A. (2000), "Language Use and Maintenance among the Moroccan Minority in Britain”, Phd Thesis. The School of Languages, University of Saltford, Salford UK.

Jagodic, D. (2012), "Between Language Maintenance and Language Shift: The Slovenian Community in Italy Today and Tomorrow", Slovene Research Institute - SLORI. ESUKA -JEFUL 2011, 2 - 1: 195 - 213.

Kedrebeogo, G. (1998), "Language maintenance and language shift in Burkina Faso: The case of the Koromba", Studies in the Linguistic Sciences Volume 28, Number 2.

Kloss, H. (2004), "The Dynamics of German Language Maintenance in Canada", http://www.forumduetsch.ca/Sonderteil/Dokmente/The_dynamics of German language maintenance in Canada-20-Sociocultural political and religio

Mesthrie, R., Swann.J., Duemert. A., \& Leap, William, (2000), “English in Language shift”, Edinburgh: University Of Edinburgh Press.

Myers-Scotton. C. (2006), "Multiple Voices: An introduction to Bilingualism", Malden-Blackwell Publishing Ltd.

Newman, L. (2005), "The endangered language issue as a hopeless cause". In: Janse, Mark, and Tol,Sijmen (eds), Language Death and Language Maintenance: Theoretical, practical and descriptive approaches.

Amsterdam: John Benjamins Publishing Company.

Thomson, S.G., (2001), “Language Contact: An Introduction”, Washington D.C: Georgetown, University Press.

Trudgill, P., (1998). The chaos before the order: New Zealand English and the second stage of new-dialect formation”, In: Jahr, Ernst Håkon, (ed.), Advances in historical sociolinguistics. Berlin, 1-11.

Veltman, C. (1983), "Language Shift in the United States", Berlin: Mouton de Gruyter.

Veltman, C. (1991), "Theory and method in the study of language shift", In J.R. Dow (Ed.), Language and Ethnicity: Focus schrift in honour of Joshua, A. Fishman, Philadelphia: John Benjamins Publishing Company, pp. 145- 167.

Wardhaugh, R. (1987). “An Introduction to Sociolinguistics”, Oxford: Blackwell Publishers.

\section{Appendix}

SECTION A:

BIO-DATA

Please tick the response that is most appropriate $(\sqrt{ })$ to you.
1. Gender:
(a) Male ( $\quad($ )
(b) Female $(\quad)$
2. Age:
(a) 20years and below ( )
(b) $21-30 \quad(\quad)$
(c) $31-40 \quad(\quad)$
(d) 41-50
(e) Above 50 years

3 . Where do you come from?.

4. Where were you born?

5. How long have you stayed in Accra?

6. Have you stayed in other place (s) apart from Accra? Yes ( ) No ( $)$

7. If your answer is yes, please write the other place (s) you stayed and the days, months or years you spent there.

\section{Place}

i...

ii.

iii.

\section{Duration}

8. What is your level of education?

$\left.\begin{array}{lll}\text { i. None }( & \text { ii. J.S.S } & ( \\ \text { iii. S.S.S } & (\quad) & \text { iv Vocational }( \\ \text { v Tertiary }( & & \end{array}\right)$

9. What work do you do? 


\section{SECTION B LANGUAGE SKILLS}

1. What is your mother's native language?.

2. What is your father's native language?

3. How many languages do you speak?.

4. Which of the language(s) did you learn first, second, third,...?

First.

Second.

Third.

Fourth.

Fifth.

Please list the languages you speak according to how good you are in each of them

a.

b.

c.

d.

e.

f......

g......

5 . Where did you learn your language(s) from?

Language

i.

ii...................................

iii................................

iv................................

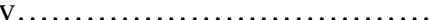

6. Which of the languages is mostly used in your area?

7. Why did you learn these languages?

Language

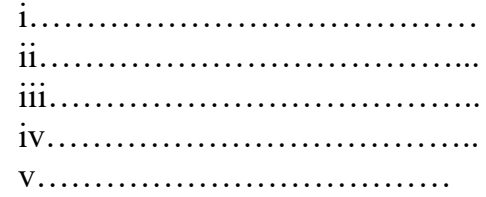

\section{where you learnt the language}

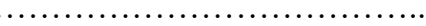

\section{SECTION C DOMAIN OF LANGUAGE USE}

1. Which language (s) do you speak with the following people?

Language (s)

People

Mother

Father

Siblings

Friends

Children

Strangers

2. Which language(s) do you use at the following places?

\section{Language}

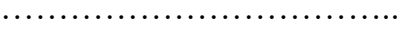

n..........................

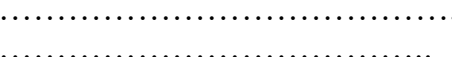

(n)
Place

Home

Community

Work place

School

Church/Mosque

Market / Shop

Hospitals

\section{SECTION D- ATTITUDE TOWARDS}

1. Do you consider yourself good in Ga? i. Yes ( ) ii. No ( )

2. Do you mix Ga and some other languages when you speak? i.Yes ( ) ii No ( ) 2 b why?

3. Do you feel comfortable speaking Ga in all places? i.Yes ( ) ii No ( )

4. Are you forced in anyway to speak Ga by Gas? i.Yes ( ) ii No ( ) 
5 Have you felt a need to shift from the use of Ga to other languages? iYes ( ) ii No ( )

5b. Why?

6. Have you felt a need to maintain using $\mathrm{Ga}$ ?

6b. Why?

7. Do you think it is important that everyone in Accra should learn Ga? I Yes ( ) ii No ( 7b.Why?. 